\title{
Quantification of hysteresis effects on a soil subjected to drying and wetting cycles
}

\author{
Samia Rafraf ${ }^{1 *}$, Lamia Guellouz ${ }^{1}$ Houda Guiras ${ }^{2}$, and Rachida Bouhlila ${ }^{1}$ \\ ${ }^{1}$ Laboratoire de Modélisation en Hydraulique et Environnement, \\ ${ }^{2}$ Laboratoire de Génie Civil, Université de Tunis El Manar, \\ Ecole Nationale d'Ingénieurs de Tunis, Université de Tunis El Manar, BP 37, Le Belvédère, 1002 Tunis, Tunisia
}

Received January 5, 2016; accepted September 21, 2016

\begin{abstract}
A b s t r a c t. A quantitative description of soil hysteretic response during drying-wetting cycles is required to improve prediction of the soil water retention model. The objective of the study is to quantify the degree of hysteresis, which is helpful to evaluate the precision of soil water flow calculation. A new procedure to quantify the degree of hysteresis is presented. The Arya-Paris model allows assessment of hysteresis effects from initial drying curves, dynamic contact angles, degree of hysteresis value, and maximum difference value between drying and subsequent wetting curves. The experimental results show that the degree of hysteresis varies with the particle size, bulk density, void ratio, initial water content, and contact angle of the soil. The new findings can be very useful in modelling soil water flows.

$\mathrm{K}$ e y w o r d s: water retention curve, degree of hysteresis, drying-wetting cycles, soil
\end{abstract}

\section{INTRODUCTION}

Understanding and modelling flow problems in unsatuted soils are very important in several fields, such as prediction of groundwater recharge or contaminant transport through unsaturated soils.

Hysteresis in the soil water retention curve (SWRC) refers to the non-unique curve in wetting or drying paths (Haines, 1930). That means that two different values of water content can correspond to the same matric potential (Hillel, 1998). Such a phenomenon is thought to be caused by numerous factors, such as nonuniformity in pore crosssections (ink-bottle effect), variation of dynamic contact angles in the advancing or receding water-air interface menisci, and entrapped air volume changes (Maqsoud et al., 2004).

\footnotetext{
*Corresponding author e-mail: samia.rafraf81@gmail.com
}

Many researchers, eg Fayer, 2000; Hilfer, 2006; Simunek et al., 2008; and Rudiyanto et al., 2015, assume that taking into account soil hysteresis improves the modelling of flow in unsaturated soils.

Laboratory experiments for characterizing hysteresis in soil water retention curves (SWRC) are still difficult and expensive due to the relatively long time necessary to its determination. However, some works focused on the hysteresis phenomenon in SWRC (Konyai et al., 2006; Li, 2005; Pham et al., 2003; Witkowska-Walczak, 2006).

This work consists in two parts: an experimental study dealing with cyclic drying and wetting paths and a theoretical study to determine soil hysteretic magnitude effects. The Arya and Paris (AP) model (1981) is used for modelling the soil water retention curve.

This paper starts with the description of the experimental work carried out to characterize the magnitude of the hysteresis. The following section deals with the basic equations. Then the effect of some soil properties (the particle size, bulk density, initial water content and contact angle) on soil hysteresis are discussed.

\section{MATERIALS AND METHODS}

Soil samples with different bulk densities, in slurry and compacted states, were prepared. These samples were subjected to successive wetting-drying cycles from full saturation to air-dry state. This procedure allowed soil samples to reach an equilibrium (stable physical characteristics) (Guiras, 1996). The main properties of the studied soil are shown in Table 1.

(C) 2016 Institute of Agrophysics, Polish Academy of Sciences 
T a b l e 1. Soil properties

\begin{tabular}{lc}
\hline Properties & Value \\
\hline Specific gravity Gs $(-)$ & 2.72 \\
Liquid limit (\%) & 60 \\
Plastic limit (\%) & 25 \\
Plasticity index (\%) & 35 \\
Specific area, $\left(\mathrm{m}^{2} \mathrm{~g}^{-1}\right)$ & 2.5 \\
Amount of carbonates $(\%)$ & 29 \\
\hline
\end{tabular}

In this study, we carried out five cycles of WRC for soil at a slurry state and three cycles of WRC for soil at two different compacted states. The soil water retention curves were determined using a climatic chamber with a constant temperature $\left(\mathrm{T}=20^{\circ} \mathrm{C}\right)$ and regulation of relative humidity according to Table 2 . The degree of hysteresis was calculated and analysed from the drying and wetting processes for all cycles.

The AP model requires a reasonably well defined grainsize distribution based on the capillary theory and the hypothesis of spherical particles and cylindrical pores.

The void volume, $V_{v i}\left(\mathrm{~g}^{-1} \mathrm{~cm}^{3}\right)$, associated with the solid mass in the $i$ th particle size is:

$$
V_{v i}=\frac{P_{i}}{G_{s} \rho_{w}} e,
$$

where: $P_{i}$ - represents solid mass per unit sample mass in the $i$ th particle-size range $\left(\mathrm{g} \mathrm{g}^{-1}\right), e$ - void ratio, $\rho_{w}$ - water density $\left(\mathrm{g} \mathrm{cm}^{-3}\right), G_{s}$ - specific gravity of the soil.

The volumetric water content $w_{w}$ is:

$$
w_{v i}=\frac{\sum_{j=1}^{i} V_{v j}}{V},
$$

where $V$ is the total volume.
The number of particles in the i-th fraction can be calculated by:

$$
N_{i}=\frac{3 P i}{4 \pi G_{s} \rho_{w} R_{i}^{3}},
$$

where: $N_{i}$-number of spherical particles in its particle-range.

The pore radius $\left(r_{i}\right)$ (Arya-Paris, 1981) is calculated by:

$$
r_{i}=R_{i}\left[\frac{4 e N_{i}^{(1-\alpha)}}{6}\right]^{\frac{1}{2}},
$$

where $\alpha$ is an empirical parameter (Arya-Paris, 1981).

The AP theory and derivation is explained in detail in (Arya and Paris, 1981).

The soil matric potential is calculated by Jurin Law:

$$
s_{i}=\frac{2 \sigma_{s} \cos \theta}{\rho_{w} g r_{i}},
$$

where: $s_{i}$ - matric potential $(\mathrm{kPa}), \sigma_{s}$ - surface tension of pore water $\left(\mathrm{N} \mathrm{m}^{-1}\right), \theta$ - liquid-solid contact angle (radians); $g$ - gravitational acceleration $\left(\mathrm{m} \mathrm{s}^{-2}\right)$.

The hysteresis between a drying and a wetting curve cannot be neglected. Therefore, a hysteresis region represents the irreversible energy dissipated by eliminating the fluid when drying, which is different from the condensation of the fluid when wetting. Hence, the degree of hysteresis is the difference between the two branches (wetting and drying). Three methods were used to determine the hysteresis magnitude of the different drying-wetting cycles.

For each cycle, the degree of the hysteresis value at a chosen particle diameter was calculated by the ratio of the difference between maximum matric potential on the wetting curve and on the drying one (or inversely) to the difference between $s_{s}$ and $s_{r}$ (matric potential at saturated

\begin{tabular}{|c|c|c|c|c|}
\hline \multirow{3}{*}{$\begin{array}{l}\text { Cycle number } \\
\text { Cycle } 1\end{array}$} & \multicolumn{4}{|c|}{ Relative humidity range (\%) } \\
\hline & \multicolumn{2}{|c|}{ Soil in slurry state } & \multicolumn{2}{|c|}{ Soil in compacted state } \\
\hline & $\begin{array}{l}\text { Initial drying } \\
\text { from } 95 \text { to } 18\end{array}$ & $\begin{array}{l}\text { Main wetting } \\
\text { from } 18 \text { to } 75\end{array}$ & $\begin{array}{l}\text { Scanning drying } \\
\text { from } 95 \text { to } 18\end{array}$ & $\begin{array}{l}\text { Scanning wetting } \\
\text { from } 18 \text { to } 75\end{array}$ \\
\hline Cycle 2 & $\begin{array}{l}\text { Main wetting } \\
\text { from } 18 \text { to } 75\end{array}$ & $\begin{array}{l}\text { Main drying } \\
\text { from } 75 \text { to } 30\end{array}$ & $\begin{array}{l}\text { Scanning wetting } \\
\text { from } 18 \text { to } 75\end{array}$ & $\begin{array}{l}\text { First drying } \\
\text { from } 75 \text { to } 30\end{array}$ \\
\hline Cycle 3 & $\begin{array}{l}\text { Main drying } \\
\text { from } 75 \text { to } 30\end{array}$ & $\begin{array}{l}\text { First wetting } \\
\text { from } 30 \text { to } 95\end{array}$ & $\begin{array}{l}\text { First drying } \\
\text { from } 75 \text { to } 30\end{array}$ & $\begin{array}{l}\text { First wetting } \\
\text { from } 30 \text { to } 95\end{array}$ \\
\hline Cycle 4 & $\begin{array}{l}\text { First wetting } \\
\text { from } 30 \text { to } 95\end{array}$ & $\begin{array}{l}\text { Firs drying } \\
\text { from } 95 \text { to } 38\end{array}$ & - & - \\
\hline Cycle 5 & $\begin{array}{l}\text { First drying } \\
\text { from } 95 \text { to } 38\end{array}$ & $\begin{array}{l}\text { Second wetting } \\
\text { from } 38 \text { to } 73\end{array}$ & - & - \\
\hline
\end{tabular}
and residual conditions, respectively), written for each cycle in an equation form as:

- for the first cycle (initial drying/main wetting):

T a b l e 2. Experimental scheme to determine SWRC 


$$
H_{1}^{C 1}=\frac{\Delta s_{d \max }}{S_{r}-s_{s}},
$$

- for the second cycle (main wetting/main drying):

$$
H_{1}^{C 2}=\frac{\Delta s_{w \max }}{s_{s}-s_{r}},
$$

- for scanning (drying/ wetting) cycles, the degree of the hysteresis value is:

$$
H_{1}^{C i d}=\frac{\Delta s_{d \max }}{s_{r}-s_{s}},
$$

- for scanning (wetting/drying) cycles, the degree of the hysteresis value is:

$$
H_{1}^{C i w}=\frac{\Delta s_{w \max }}{s_{s}-s_{r}}
$$

where: $H_{1}^{C 1}, H_{1}^{C 2}, H_{1}^{C i d}$ and $H_{1}^{C^{C i w}}$ : degree of hysteresis values; $\Delta s_{d \max }-$ maximum difference of matric potential (between drying/wetting curves); $\Delta s_{w_{\max }}$ - maximum difference of matric potential (between wetting/drying curves) - we define $\left(k_{i}\right)$ the ratio between the pore radius $\left(r_{i d}\right)$ at a drying curve and pore radius $\left(r_{i w}\right)$ at a subsequent wetting curve as:

$$
k_{i}=\frac{r_{i d}}{r_{i w}} .
$$

Introducing Eqs (3) and (4) in Eq. (10), we obtain:

$$
k_{i}=\sqrt{\frac{e_{d}}{e_{w}}\left[\frac{N_{i t}}{N_{i w}}\right]^{(1-\alpha)}}=\sqrt{\frac{e_{d}}{e_{w}}},
$$

where: $e_{d}$ and $e_{w}$ are void ratios at the drying and wetting path respectively; $N_{i d}$ and $\mathrm{N}_{i w}$ are the number of particles in the $\mathrm{i}$-th fraction at the drying and wetting path respectively, according to Eq. (3) $\left(N_{i d}=N_{i w}\right) ; \alpha$-Arya-Paris (1981) scale factor calculated from the initial drying curve.

- For the first cycle (initial drying-main wetting), based on Eq. (6) the degree of hysteresis $H_{1}^{C 1}$ can be calculated as:

$$
H_{1}^{C 1}=\left(1-k_{1} \cos \left(\theta_{a}\right) \frac{s_{d \max }}{s_{r}-s_{s}},\right.
$$

where: $\theta_{a}$ - advancing contact angle, $S_{d \max }$ - maximal matric potential at the initial drying curve, $k_{1}$ - is the ratio between the pore radius $\left(r_{i d}\right)$ at the initial drying curve and $\left(r_{i w}\right)$ at the main wetting curve, from Eq. (11).

For the second cycle (main wetting-main drying), based on Eq. (7) the degree of hysteresis $H_{1}^{C 2}$ can be calculated as:

$$
H_{1}^{C 2}=\left(1-k_{2} \frac{\cos \left(\theta_{r}\right)}{\cos \left(\theta_{a}\right)}\right) \frac{s_{w \max }}{s_{s}-s_{r}},
$$

where: $\theta_{r}$ - receding contact angle, $S_{w \max }$ - maximal matric potential at the main wetting curve, $k_{2}$-is the ratio between the pore radius $\left(\mathrm{r}_{i d}\right)$ at the main wetting curve and $\left(r_{i w}\right)$ at the main drying curve, from Eq. (11).

- For a subsequent scanning (drying/ wetting) cycle, based on Eq. (8) the magnitude of hysteresis $H_{1}^{\text {Cid }}$, written in an equation form as:

$$
H_{1}^{C i d}=\left(1-k_{3} \frac{\cos \left(\theta_{r i}\right)}{\cos \left(\theta_{a i}\right)}\right) \frac{s_{d \max }}{s_{r}-s_{s}},
$$

where $S_{d \max }$ - maximal matric potential at the scanning drying curve, $\theta_{a i}$ and $\theta_{r i}$ are respectively the advancing and receding contact angle for a scanning (drying/wetting) cycle $\mathrm{i}, k_{3}-$ is the ratio between the pore radius $\left(r_{i d}\right)$ at the scanning drying curve and $\left(r_{i w}\right)$ at the scanning wetting curve, from Eq. (11).

- For a subsequent scanning (wetting/drying) cycle, based on Eq. (9) the magnitude of hysteresis $H_{1}{ }^{C i w}$, written in an equation form as:

$$
H_{1}^{C i w}=\left(1-k_{2} \frac{\cos \left(\theta_{r i}\right)}{\cos \left(\theta_{a i}\right)}\right) \frac{s_{w \max }}{s_{s}-s_{r}} .
$$

The degree of the hysteresis value at a chosen particle diameter can be defined as the ratio of the difference between the maximum volumetric water content on the wetting curve and on the drying one to the difference between $w_{S}$ and $w_{r}$ (volumetric water content at the saturated and residual conditions, respectively), written in an equation form as:

$$
H_{2}=\frac{\Delta w_{\max }}{w_{s}-w_{r}},
$$

where: $H_{2}$ - degree of hysteresis, $\Delta w_{\max }$ - maximum difference of water content (between drying/wetting curves).

The hysteresis magnitude at a chosen particle diameter can also be defined as the ratio of the maximum difference of matric potential to the average of maximum matric potential and written in an equation form as:

$$
H_{3}=\frac{\Delta s_{d \max }}{s_{\text {moyen }}},
$$

where: $H_{3}$ - degree of hysteresis, $\Delta S_{d \max }=S_{d \max }-S_{w \max }$ - maximum difference of matric potential between drying $\left(S_{d \max }\right)$ and wetting $\left(S_{w \max }\right)$ curves, $S_{\text {moyen }}$ - average of maximum matric potential (between drying/wetting curves). 


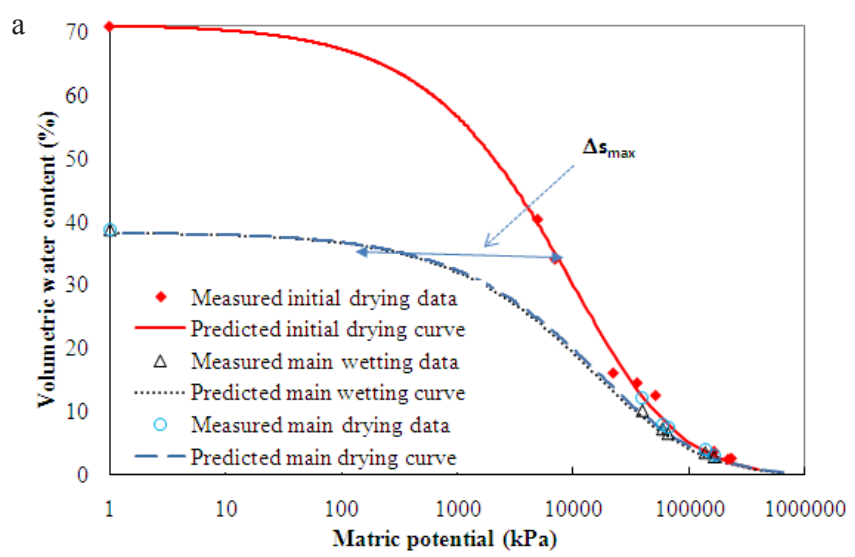

$\mathrm{b}$

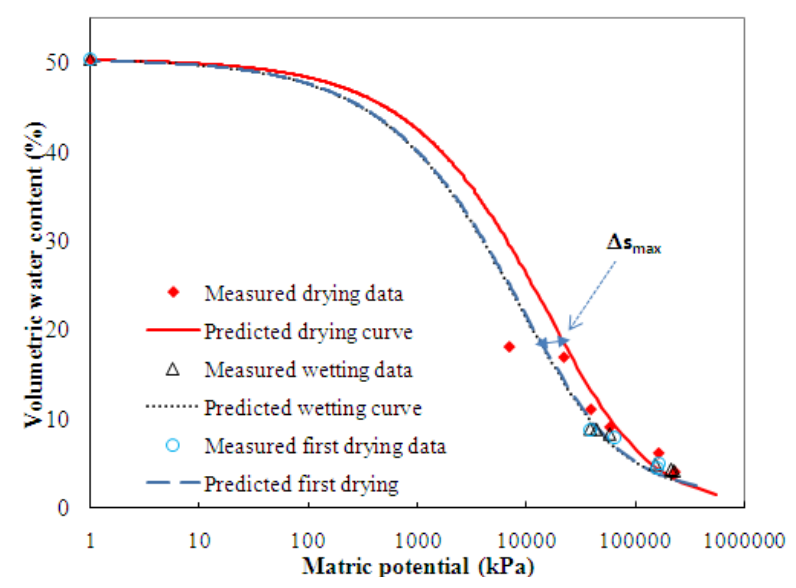

$\mathrm{c}$

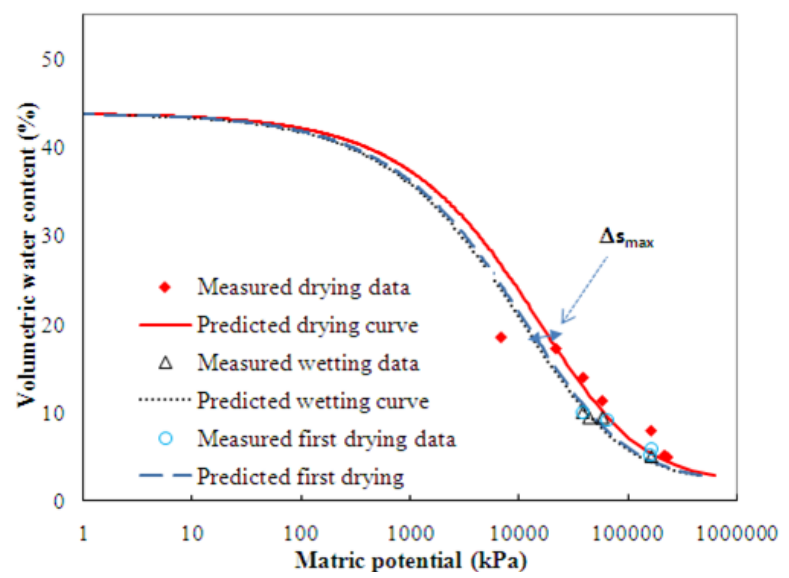

Fig. 1. The hysteretic soil-water retention curves (SWRC) for the slurry state: $\mathrm{a}$ - initial bulk density $\left(\rho_{d}=0.79 \mathrm{~g} \mathrm{~cm}^{-3}\right)$, the compacted states; $\mathrm{b}-$ initial bulk density $\left(\rho_{d}=1.35 \mathrm{~g} \mathrm{~cm}^{-3}\right)$; and $\mathrm{c}-$ initial bulk density $\left(\rho_{d}=1.53 \mathrm{~g} \mathrm{~cm}^{-3}\right)$ of the studied soil.

\section{RESULTS AND DISCUSSIONS}

The soil water retention curves, obtained experimentally, for three different bulk densities are shown in Fig. 1. The fitted AP model for the soil water retention curves are also shown in Fig. 1. The parameters of the AP model are presented in Table 3. The calculated values of the degree of hysteresis using method 1 and the maximum matric potentials as well as some soil parameters are shown in Table 4.
T a b l e 3. Arya-Paris (1981) model initial parameters for the drying curve

\begin{tabular}{|c|c|c|c|}
\hline \multirow{2}{*}{$\begin{array}{l}\text { Properties } \\
\text { Bulk density }\left(\mathrm{g} \mathrm{cm}^{-3}\right)\end{array}$} & \multirow{2}{*}{$\begin{array}{c}\begin{array}{c}\text { Soil in } \\
\text { slurry state }\end{array} \\
0.79\end{array}$} & \multicolumn{2}{|c|}{ Soil in compacted states } \\
\hline & & 1.53 & 1.35 \\
\hline $\begin{array}{l}\text { Saturated volumetric } \\
\text { water content }(\%)\end{array}$ & 71 & 44 & 50 \\
\hline Void ratio & 2.46 & 0.78 & 1.01 \\
\hline $\begin{array}{l}\text { Matric potential at } \\
\text { saturation }\left(s_{s}\right)(\mathrm{kPa})\end{array}$ & 0.74 & 0.63 & 0.55 \\
\hline Empirical parameter $\alpha$ & & 1.38 & \\
\hline
\end{tabular}

a

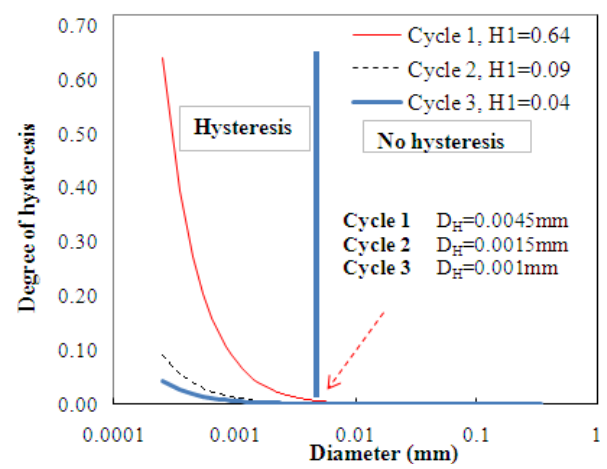

Cycle 1: $H_{1}$ calculated from (Eq. (6)); Cycle 2: $H_{1}$ calculated from (Eq. (7)); Cycle 3: $\mathrm{H}_{1}$ calculated from (Eq. (8)).

b

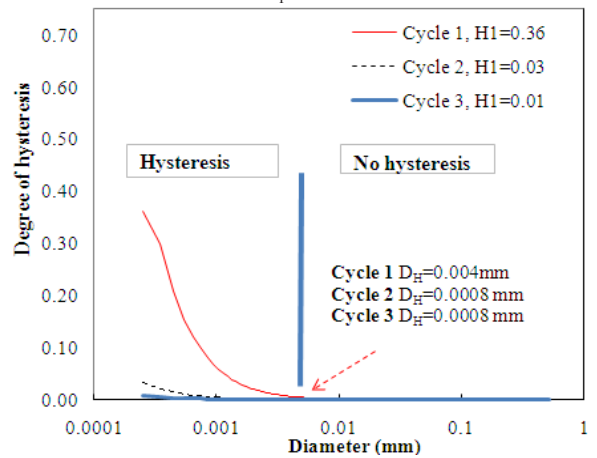

Cycle 1 and Cycle 3: $\mathrm{H}_{1}$ calculated from (Eq. (8)); Cycle 2: $\mathrm{H}_{1}$ calculated from (Eq. (9)).

$\mathrm{c}$

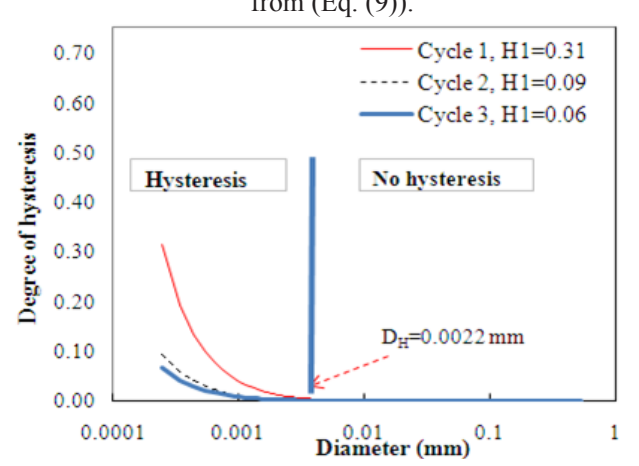

Cycle 1 and Cycle 3: $\mathrm{H}_{1}$ calculated from (Eq. (8)); Cycle 2: $\mathrm{H}_{1}$ calculated from (Eq. (9)).

Fig. 2. The cyclic relationship between degree of hysteresis $\left(H_{1}\right)$ and particle size for: $\mathrm{a}$ - slurry state, $\mathrm{b}$ - compacted state $(\mathrm{e}=1.01)$ and $\mathrm{c}-$ compacted state $(\mathrm{e}=0.78), \mathrm{DH}-\operatorname{diameter}(\mathrm{mm})$. 
T a b l e 4. Values of degree of hysteresis, maximum matric potentials and soil parameters in SWRC

\begin{tabular}{|c|c|c|c|c|c|c|c|c|c|}
\hline \multirow{2}{*}{\multicolumn{2}{|c|}{ Cycle number }} & \multicolumn{2}{|c|}{$\begin{array}{c}\text { Maximum matric } \\
\text { potential }(\mathrm{kPa})\end{array}$} & \multicolumn{2}{|c|}{$\begin{array}{c}\text { Degree of hysteresis } \\
\text { Method } 1\end{array}$} & \multicolumn{2}{|c|}{ Contact angle $\left(^{\circ}\right)$} & \multirow{2}{*}{$\begin{array}{l}\text { Initial saturated } \\
\text { volumetric } \\
\text { water content } \\
(\%)\end{array}$} & \multirow{2}{*}{$\begin{array}{c}k_{i} \\
(\mathrm{Eq} .10)\end{array}$} \\
\hline & & $\begin{array}{l}\text { drying } \\
\text { curve }\end{array}$ & $\begin{array}{l}\text { wetting } \\
\text { curve }\end{array}$ & $\begin{array}{c}\text { equation } \\
\text { used }\end{array}$ & value & $\begin{array}{l}\text { drying } \\
\text { curve }\end{array}$ & $\begin{array}{l}\text { wetting } \\
\text { curve }\end{array}$ & & \\
\hline \multirow{5}{*}{$\begin{array}{l}\text { Soil in } \\
\text { slurry state } \\
(\mathrm{e}=2.46)\end{array}$} & Cycle 1 & 357442 & 586607 & $(12)$ & 0.64 & 0 & 34 & 71 & 1.99 \\
\hline & Cycle 2 & 638705 & 586607 & (13) & 0.09 & 26 & 34 & 38 & 1 \\
\hline & Cycle 3 & 638705 & 611354 & (14) & 0.04 & 26 & 31 & 38 & 1 \\
\hline & Cycle 4 & 618280 & 611354 & (15) & 0.01 & 30 & 31 & 38 & 1 \\
\hline & Cycle 5 & 618280 & 618988 & (14) & 0 & 30 & 30 & 38 & 1 \\
\hline \multirow{3}{*}{$\begin{array}{l}\text { Soil in } \\
\text { compacted } \\
\text { state } \\
(\mathrm{e}=1.01)\end{array}$} & Cycle 1 & 556085 & 355052 & (14) & 0.36 & 0 & 50 & 50 & 1 \\
\hline & Cycle 2 & 367016 & 355052 & $(15)$ & 0.03 & 49 & 50 & 50 & 1 \\
\hline & Cycle 3 & 367016 & 363680 & (14) & 0.01 & 49 & 49 & 50 & 1 \\
\hline \multirow{3}{*}{$\begin{array}{l}\text { Soil in } \\
\text { compacted } \\
\text { state } \\
(\mathrm{e}=0.78)\end{array}$} & Cycle 1 & 635195 & 436697 & (14) & 0.31 & 0 & 47 & 44 & 1 \\
\hline & Cycle 2 & 476396 & 436697 & (15) & 0.09 & 41 & 47 & 44 & 1 \\
\hline & & 476396 & 445571 & (14) & 0.06 & 41 & 45 & 44 & 1 \\
\hline
\end{tabular}

e - void ratio.

The degree of hysteresis versus the particle size value is plotted for each cycle in Fig. 2. The values of the degree of hysteresis calculated by means of the three described methods for the soil slurry state are plotted in Fig. 3.

The soil used in this study shows a hysteretic behaviour (Fig. 1). The degree of hysteresis varies with bulk density and void ratio as shown in Figs 1 and 2, respectively. The degree of the hysteresis value becomes zero for a particle diameter higher than the specific particle size $\left(D_{H}\right)$, as seen in Fig. 2. The results in Table 4 allowed us to validate the described procedure and to calculate the cyclic dependent degree of hysteresis (Eqs from (12) to (15)), with the calculated degree of hysteresis values from experimental data fitted with the AP model (Eqs from (6) to (9) for each cycle) (Fig. 3).

Local pore structure and local connectivity plays a leading role in the trapping mechanism (Geistlinger et al., 2014). Due to the trapping mechanism caused by the main wetting process, using method 2 (Eq. (16)), the maximum differences in the volumetric water content between initial drying and main wetting processes at the same soil matric potential reach nearly $46 \%$ in the first cycle and zero for the subsequent cycles as in Fig. 3. Method 3 gives similar results as method 1 , only in cycle 1 it has different values, as seen in Fig. 3. The degree of hysteresis value decreases with the increasing cycle number as shown in Fig. 2 . Results in Table 4 allowed us to conclude that the degree of hysteresis depends on the contact angle and initial saturated water content.
This finding helps in modelling unsaturated flow. Generally, the initial drying retention curve can be obtained directly from the experiments and allows the calculation of the AP scaling factor (Eq. (4)) and the ratio $\left(k_{i}\right)$ (Eq. (11)). The degree of hysteresis can thus be obtained from Eq. (12) and using contact angle value. The value of the maximum difference can be determined from Eq. (6). Thus, the main wetting curve can be formulated. Similarly, the hysteresis loop can be constructed from the initial drying curve, dynamic contact angles, degree of hysteresis value, and the maximum difference value. For subsequent cycles, we can calculate the degree of hysteresis value with Eqs (13), (14) and (15). Finally, the effect of hysteresis for each cycle can be estimated and evaluated by the maximum difference value between drying and subsequent wetting curves (Eq. from (6) to (9)).

\section{CONCLUSIONS}

1. This paper is an attempt to quantify the soil hysteretic effects caused by wetting-drying cycles. The study on the influence of the initial void ratio, particle size, contact angle, and initial water content on the degree of hysteresis values showed that their impacts are significant and the negligence of the hysteresis effect may cause inaccuracies of estimation of soil water retention curves. In fact, the soil hysteretic effect is the result of three distinct phenomena: thermodynamics, because of the dissipation of energy when 
a

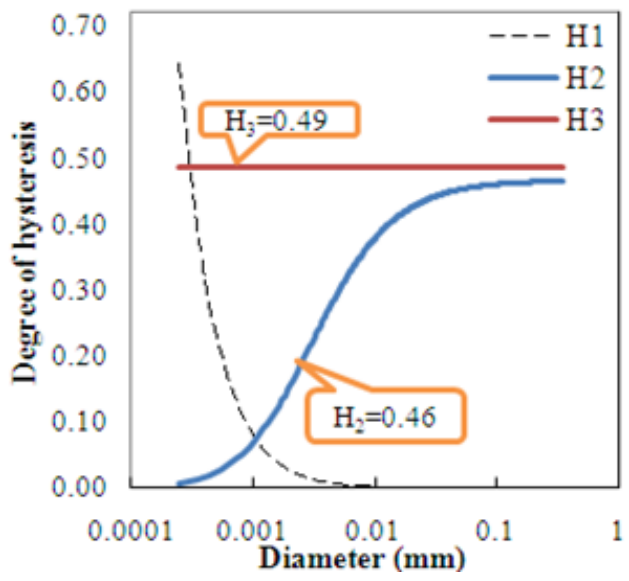

C

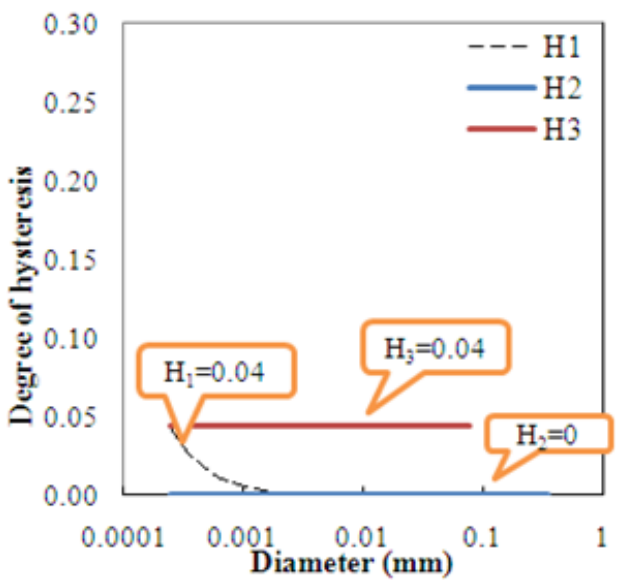

b

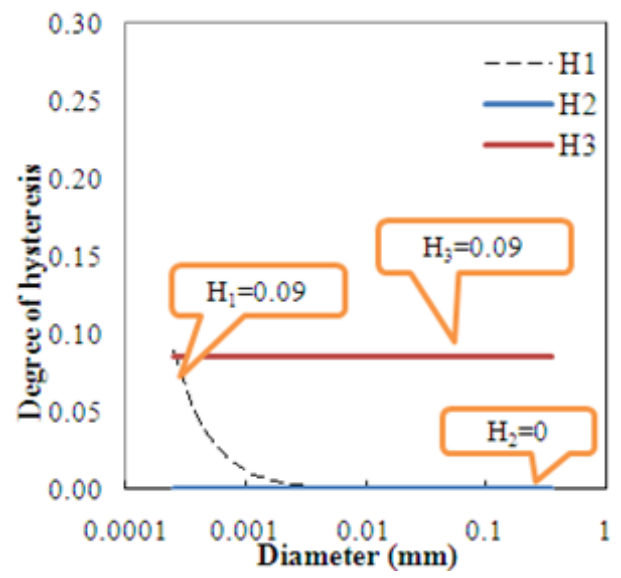

d

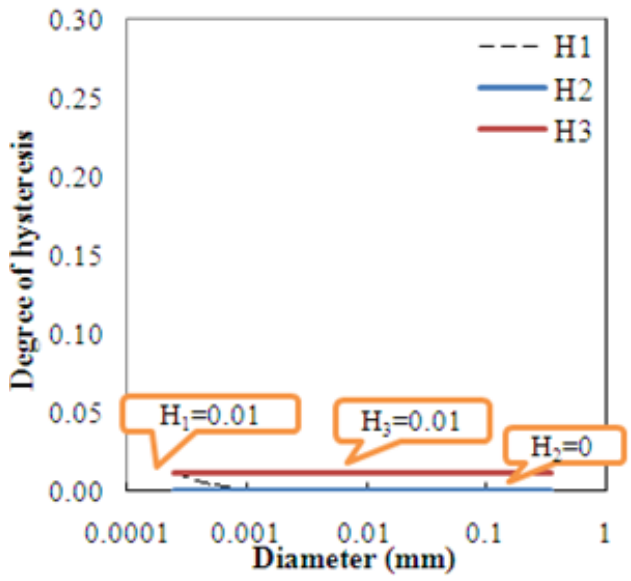

e

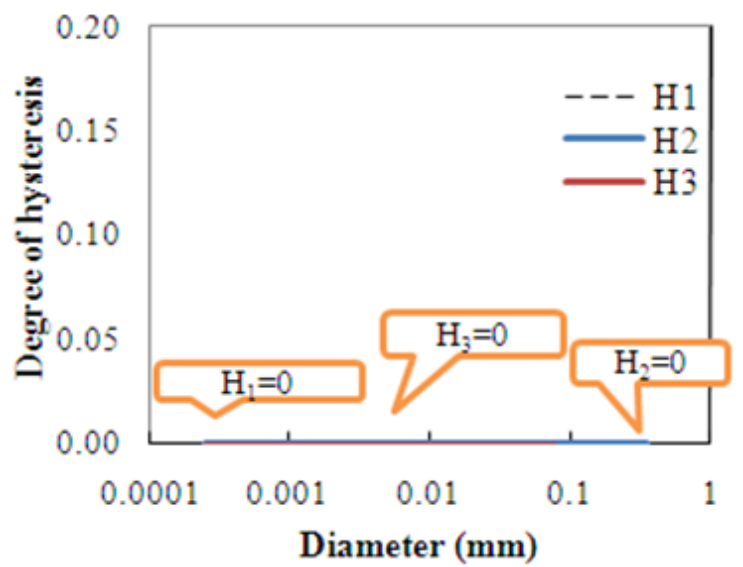

Fig. 3. The relationship between the degree of hysteresis and particle diameter using the three described methods $\left(\mathrm{H}_{1}, \mathrm{H}_{2}\right.$, and $\left.\mathrm{H}_{3}\right)$ for five cycles of the slurry state clay: a - Cycle $1\left(\mathrm{H}_{1}\right.$ calculated from (Eq. (6)), b - Cycle $2\left(\mathrm{H}_{1}\right.$ calculated from (Eq. (7)), c - Cycle 3 $\left(\mathrm{H}_{1}\right.$ calculated from (Eq. (8)), d-Cycle 4 ( $\mathrm{H}_{1}$ calculated from (Eq. (9)), e - Cycle 5 ( $\mathrm{H}_{1}$ calculated from (Eq. (8)). 
moving the wetting fluid (contact angle), geometric factor due to initial porosity (bulk density or void ratio), and the particle size distribution.

2. The experimental data have shown that the degree of the hysteresis effect under cyclic drying and wetting behaviour can be estimated by the initial drying curve, dynamic contact angles, degree of hysteresis value, and the maximum difference value between wetting and subsequent drying curves.

3. One of the advantages of the model used to quantify the hysteresis effect is that it has a clear physical meaning. Its parameters can be determined using particle size distribution, initial state, and saturated state. It can accurately describe soil hysteresis effects under cyclic drying and wetting behaviour related to the water retention curves; hence, it should be taken into account in water retention curves modelling and flow calculation.

Conflict of interest: The Authors do not declare conflict of interest.

\section{REFERENCES}

Arya L.M. and Paris J.F., 1981. A physical, empirical model to predict the soil moisture characteristics from particle-size distribution and bulk density data. Soil Sci. Soc. Am. J., 45, 1023-1030.

Fayer M.J., 2000. UNSAT-H Version 3.0: Unsaturated Soil Water and Heat Flow Model: Theory, User Manual, and Examples, Pac. Northwest. Natl. Lab., Richland, Wash.

Geistlinger H., Mohammadian S., Schlüter S., and Vogel H.-J., 2014. Quantification of capillary trapping of gas clusters using X-ray microtomography. Water Resources Res., 50, 4514-4529.
Guiras Skandaji, 1996. Déformabilité des sols argileux non saturés: étude expérimentale et application à la modélisation. Thèse de doctorat, Ecole Nationale Supérieure de Géologie de Nancy, France.

Haines W.B., 1930. Studies in the physical proprieties of soil : V. The hysteresis effect in capillary proprieties, and the modes of moisture distribution associated therewith. J. Agricultural Sci., 20, 97-116.

Hilfer R., 2006. Macroscopic capillarity and hysteresis for flow in porous media. Phys. Rev. E., 73(1), 016307.

Hillel D., 1998. Environmental soil physics. Academy Press, Sandiego, CA, USA.

Konyai S., Sriboonlue V., Trelo-ges V., and Muangson N., 2006. Hysteresis of water retention curve of saline soil. Unsaturated Soils, 1394-1404.

Li X.S., 2005. Modelling of hysteresis response for arbitrary wetting/drying paths. Comput. Geotech., 32(2), 133-137.

Maqsoud A., Bussiere B., Mbonimpa M., and Aubertin M., 2004. Hysteresis effects on the water retention curve: A comparison between laboratory results and predictive models. The Canadian Geotechnical Soc., Richmond, BC.

Pham H.Q., Fredlund D.G., and Barbour S.L., 2003. A practical hysteresis model for the soil-water characteristic curve for the soils with negligible volume change. Geotechnique, 53(2), 293-298

Rudiyanto M., Sakai M., Van Genuchten M.Th., Alazba A.A., Setiawan B.I., and Minasny B., 2015. A complete soil hydraulic model accounting for capillary and adsorptive water retention, capillary and film conductivity, and hysteresis. Water Resour. Res., 51, doi:10.1002/2015WR017703

Simunek J., Sejna M., Saito H., Sakai M., and van Genuchten M.T., 2008. The hydrus-1d software package for simulating the movement of water, heat, and multiple solutes in variably saturated media, Version 4.0, HYDRUS Software Ser. 3, Dep. of Environ. Sci., Univ. of Calif., Riverside, CA, USA.

Witkowska-Walczak B., 2006. Hysteresis between wetting and drying processes as affected by soil aggregate size. Int. Agrophysics, 20, 359-365. 